\title{
Research on bilateral reverse migration of one-group seabed sand waves in a small shallow shelf sea
}

\author{
Wenbin Jiang, Mian Lin * \\ Institute of Mechanics, Chinese Academy of Sciences, Beijing 100190, China
}

\section{A R T I C L E I N F O}

\section{Article history:}

Received 6 December 2014

Received in revised form 31 December 2015

Accepted 30 January 2016

Available online 1 March 2016

\section{Keywords:}

Small area

Sand wave

Bilateral reverse migration

Shallow shelf sea

One-group

\begin{abstract}
A B S T R A C T
Bilateral reverse migration of one-group seabed sand waves is found recently in many small sea areas and is a potential threat to the safety of many near seabed engineering structures, such as pipelines and cables. The mechanism cannot clearly be explained by existing theories. This paper focuses on the bilateral reverse migration of one-group seabed sand waves around a sand ridge in a small shallow shelf sea of the South China Seas, and presents a developed numerical model consisting of three-dimensional wave-current coupling module and sand transport module to simulate this complex phenomenon and perform relative analysis on the characteristics of the current and bilateral reverse migration formation mechanism. Taking the ocean environment characteristics of the surrounding sea area into account and with sufficient grid resolution, this model successfully depicts the process of sand wave bilateral reverse migration. Bottom friction velocity is taken as the inspecting physical quantity and divided into tidal, residual and short-term fluctuation components through harmonic analysis; with a method based on bedload transport calculation, the contributions of the above three parts are determined. It is found that long-term sand wave migration trend is primarily controlled by both tidal constituents and residual velocity. Under nonlinear pure tidal impact, the sand waves migrate southwards; the residual current is northwards and will cancel the tidal impact. When the magnitude of the residual velocity is large enough, i.e., in the western part of the sand wave area, sand waves migrate northwards; when the residual velocity is small, i.e., in the eastern part, sand waves migrate southwards and the bilateral reverse migration pattern is formed. The residual velocity distribution relates closely to the surrounding topography. This paper discloses one kind of mechanisms for bilateral reverse migration of one-group seabed sand waves, and the model and analysis framework can also be extended and applied to other similar situations to prompt deeper and more comprehensive understanding about sand wave migration.
\end{abstract}

(c) 2016 Elsevier B.V. All rights reserved.

\section{Introduction}

Seabed sand wave migration likely induces exposure and free span of seabed cables and oil/gas pipelines, which may pose danger. Therefore, research on sand wave migration is a continual focus in both engineering and academic fields. Sand waves that occur on the sandy bed in a sea area near shore belong to unstable geomorphology; their migration rates can reach from several metres to more than ten metres per year, and the migration direction is basically perpendicular to sand wave crest lines. Seabed sand waves are generally patchy or scattered in distribution. In marine geology academic investigations, the nearby sand waves with parallel crest lines are classified as a group. In general, sand waves that belong to the same group are considered to migrate in the same direction.

However, in recent years, scientists (Wang et al., 2007; Boe et al., 2009; Li et al., 2010; Franzetti et al., 2013) have found that sand waves from the same group display a bilateral reverse migration pattern

\footnotetext{
* Corresponding author. Tel.: +8610 82544206; fax: +861062561284.

E-mail address: linmian@imech.ac.cn (M. Lin).
}

in the sea areas near the coasts of China, Norway and France. "Bilateral reverse migration" relates to the nearby sand waves of the same group in a small sea area with horizontal scale of about less than several kilometres, and it seems that there is a "fictitious" axis and sand waves on the two sides of this axis migrate in the opposite direction. There isn't clear understanding of the cause of this phenomenon yet.

Near Dongfang in the Beibu Gulf of the northern region of the South China Sea, the widths of two sand wave fields are approximately $1 \mathrm{~km}$, and the distance between them is only $16 \mathrm{~km}$. The wavelength of water waves in this area can be over $40 \mathrm{~m}$. One of these sand wave fields is located between $108^{\circ} 16.5^{\prime} \mathrm{E}-108^{\circ} 17.5^{\prime} \mathrm{E}$ and $18^{\circ} 51.85^{\prime} \mathrm{N}-18^{\circ} 52.62^{\prime} \mathrm{N}$. Its area is approximately $3 \mathrm{~km}^{2}$, and its depth is approximately 25.8 $31 \mathrm{~m}$. The ratio of the mean water depth to the water wave wavelength is always larger than $1: 2$, and the area is named as wave field D. In wave field $\mathrm{D}$, a sand ridge elongates from northeast to southwest, and the width is approximately $1000 \mathrm{~m}$. Hundreds of sand waves with different sizes are distributed in this area, the wavelengths are approximately $30 \mathrm{~m}$, and the wave heights are approximately $1 \mathrm{~m}$. A comparison of survey results using a multi-beam system in 2004, 2005, 2007, and 2009 showed that sand waves to the west of the sand ridge migrate 
southwards, and sand waves to the east of the sand ridge migrate northwards reversely. The migration pattern is counter-clockwise around the sand ridge.

Another sand wave field with an area of approximately $7 \mathrm{~km}^{2}$ is located between $108^{\circ} 24.1^{\prime} \mathrm{E}-108^{\circ} 25.27^{\prime} \mathrm{E}$ and $18^{\circ} 54.43^{\prime} \mathrm{N}-18^{\circ} 57.18^{\prime} \mathrm{N}$ (Fig. 1). A sand ridge elongates from north to south in the centre of the area, and the width of the sand ridge is approximately $1000 \mathrm{~m}$ (Fig. 1). The minimum water depth at the back of the sand ridge is only $6.6 \mathrm{~m}$, and the water depth at the groove of the sand ridge reaches as high as $26.9 \mathrm{~m}$. The ratio of the mean water depth to the water wave wavelength can be lower than $1: 2$, and the area is named as sand wave field $\mathrm{S}$. The sand waves in field $\mathrm{S}$ have wavelengths between $30 \mathrm{~m}$ and $50 \mathrm{~m}$, wave heights between $1 \mathrm{~m}$ and $3 \mathrm{~m}$, and also belong to the same range of small-scale sand waves as field D. The sand waves are distributed among the sand ridge back and groove. A comparison of survey results using a multi-beam system showed that sand waves to the west of the sand ridge migrate northwards, and the sand waves on the other side of the sand ridge migrate southwards reversely. The migration pattern is clockwise around the sand ridge, which is the reverse of the pattern in field $D$.

A series of studies has been performed on sand wave migration. Németh et al. (2002, 2004, 2007), van Dijk and Kleinhans (2005), and Borsje et al. $(2009,2013)$ considered the effect of a singular M2 tide constituent and steady current (M0 represents the residual current), combined the hydrodynamic equations and sand transportation equations, and simulated the hydrodynamic process of sand wave migration. The results showed that large-scale sand waves with wavelengths from hundreds to thousands of metres migrate in the direction of the residual current. Using the same approach as Németh et al. (2002), Besio et al. (2004) considered additionally the influence of the quarter-diurnal tide constituent (M4) and found that when the phase lag between M2 and M4 fell into a certain range, the direction of sand wave migration was opposite to the direction of the residual current, but in other situations, both directions were the same. This discovery explains the phenomenon of sand waves that depart over a hundred kilometres in the English Channel and migrate along and opposite to the direction of residual current. Therefore, it is clear that the hydrodynamic feature in the sand wave area is a determining factor of the migration direction.

In the sand wave area near Dongfang, the influences of tide, monsoon, seasonal temperature and salinity variation are obvious, and there are also several passing-by typhoons every year. The available hydrodynamic features through observations are limited in spatial and temporal ranges. To what extent we have to master and consider the hydrodynamic features for analysis isn't clear at first. Since 2009, we (Lin et al., 2009; Li et al., 2011) have attempted to consider the influence of the $\mathrm{K} 1,01$, and M2 tide constituents and the monsoon-induced current on the sand wave bilateral reverse migration in field D. However, this model is only able to predict the sand wave migration in the eastern portion of field $\mathrm{D}$ and cannot reproduce the reverse migration in the western portion. It's realised that considering tide and monsoon action isn't enough, and the influence of the sand ridge topography on the bottom current and more ocean environment factors needs to be taken into consideration. Hence, in 2011, we began to construct a high-resolution three-dimensional ocean numerical model (Jiang and Lin, 2011; Jiang et al., 2014) that considers the influence of topography, tide, temperature, salinity and surface wind stresses. This model is able to predict the bilateral reverse migration in field $\mathrm{D}$, and we conclude that the high-resolution three-dimensional ocean numerical model is able to simulate the small-scale sand wave counter-clockwise bilateral reverse migration phenomenon in the sea area where the ratio of the mean water depth to the water wave wavelength is larger than 1:2.

Wave theory states that one half of the wavelength is considered as the lower limit for wave impact. Obviously, the wave influence is rather weak in field D; the water depth of over one-third of field $\mathrm{S}$ is less than $15 \mathrm{~m}$, and thus, the influence of waves is not ignorable. Therefore, the bilateral reverse migration in field $S$ is the focus of this paper.

This paper is divided into four sections. A wave-current coupling high-resolution three-dimensional ocean numerical model is built using the design of a grid nesting method and the bedload transport module in the second section. The wave-current coupling model is verified, and the calculation results and measurements of sand wave migration are compared in the third section. In the fourth section, the current field characteristic differences are analysed using the harmonic analysis method, and the mechanism of bilateral reverse migration is disclosed. Finally, a summary is provided.

\section{Wave-current coupling module}

Current simulation is based on Princeton Ocean Model (POM) (Blumberg and Mellor, 1987), using the basic control equation with the sigma coordinate system (Phillips, 1957; Blumberg and Mellor, 1978, 1987):

$$
\left\{\begin{array}{c}
\frac{\partial D U}{\partial x}+\frac{\partial D V}{\partial y}+\frac{\partial W}{\partial \sigma}+\frac{\partial \eta}{\partial t}=0 \\
\frac{\partial U D}{\partial t}+\frac{\partial U^{2} D}{\partial x}+\frac{\partial U V D}{\partial y}+\frac{\partial U W}{\partial \sigma}-f V D+g D \frac{\partial \eta}{\partial x}+\frac{g D^{2}}{\rho_{0}} \int_{\sigma}^{0}\left[\frac{\partial \rho^{\prime}}{\partial x}-\frac{\sigma^{\prime}}{D} \frac{\partial D}{\partial x} \frac{\partial \rho^{\prime}}{\partial \sigma^{\prime}}\right] d \sigma^{\prime} \\
=\frac{\partial}{\partial \sigma}\left[\frac{K_{M}}{D} \frac{\partial U}{\partial \sigma}\right]+\frac{\partial}{\partial x}\left(2 H A_{M} \frac{\partial U}{\partial x}\right)+\frac{\partial}{\partial y}\left(H A_{M}\left(\frac{\partial U}{\partial y}+\frac{\partial V}{\partial x}\right)\right)+T_{x} \\
\frac{\partial V D}{\partial t}+\frac{\partial U V D}{\partial x}+\frac{\partial V^{2} D}{\partial y}+\frac{\partial V W}{\partial \sigma}+f U D+g D \frac{\partial \eta}{\partial y}+\frac{g D^{2}}{\rho_{0}} \int_{\sigma}^{0}\left[\frac{\partial \rho^{\prime}}{\partial y}-\frac{\sigma^{\prime}}{D} \frac{\partial D}{\partial y} \frac{\partial \rho^{\prime}}{\partial \sigma^{\prime}}\right] d \sigma^{\prime} \\
=\frac{\partial}{\partial \sigma}\left[\frac{K_{M}}{D} \frac{\partial V}{\partial \sigma}\right]+\frac{\partial}{\partial x}\left(H A_{M}\left(\frac{\partial U}{\partial y}+\frac{\partial V}{\partial x}\right)\right)+\frac{\partial}{\partial y}\left(2 H A_{M} \frac{\partial V}{\partial y}\right)+T_{y} \\
\frac{\partial T D}{\partial t}+\frac{\partial T U D}{\partial x}+\frac{\partial T V D}{\partial y}+\frac{\partial T W}{\partial \sigma}=\frac{\partial}{\partial \sigma}\left[\frac{K_{H}}{D} \frac{\partial T}{\partial \sigma}\right]+\frac{\partial}{\partial x}\left(H A_{H} \frac{\partial T}{\partial x}\right)+\frac{\partial}{\partial y}\left(H A_{H} \frac{\partial T}{\partial y}\right)-\frac{\partial R}{\partial z} \\
\frac{\partial S D}{\partial t}+\frac{\partial S U D}{\partial x}+\frac{\partial S V D}{\partial y}+\frac{\partial S W}{\partial \sigma}=\frac{\partial}{\partial \sigma}\left[\frac{K_{H}}{D} \frac{\partial S}{\partial \sigma}\right]+\frac{\partial}{\partial x}\left(H A_{H} \frac{\partial S}{\partial x}\right)+\frac{\partial}{\partial y}\left(H A_{H} \frac{\partial S}{\partial y}\right)_{S}
\end{array}\right.
$$

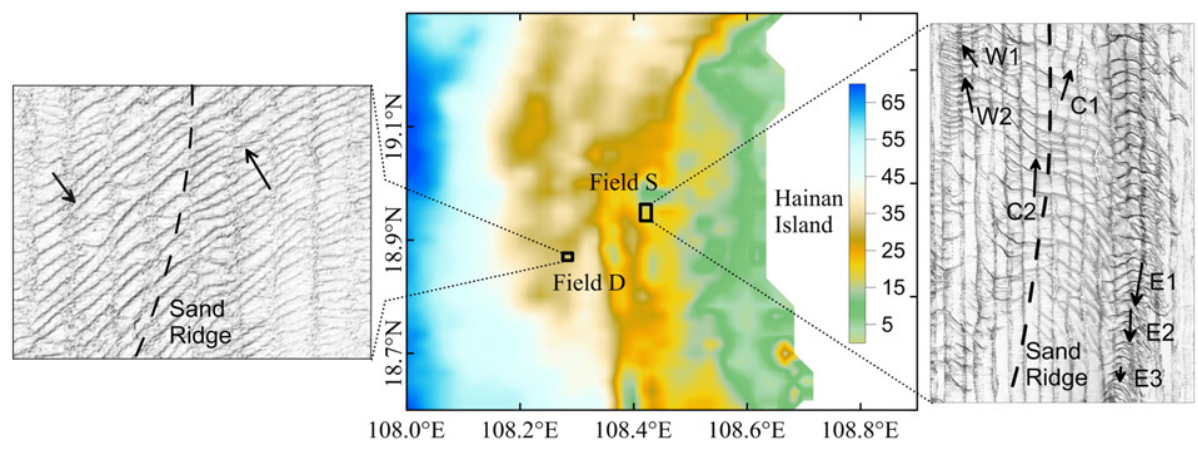

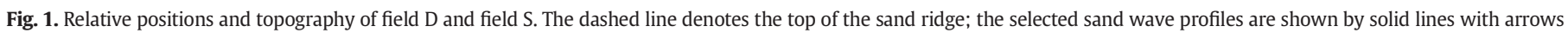
denoting the migration directions. 
where $x, y$ and $z$ are the conventional Cartesian coordinates, and $\sigma=\frac{z-\eta}{H+\eta}$; $D=H+\eta, H(x, y)$ is the local water depth and $\eta(x, y, t)$ is the surface elevation; $U$ and $V$ are the latitudinal and longitudinal velocity components, and $W$ is the velocity component normal to sigma surfaces; $\rho^{\prime}=\rho-\rho_{0}$ where $\rho$ is local density and $\rho_{0}$ is the horizontal average of initial density field; $f$ is the Coriolis parameter, $g$ is the acceleration of gravity; $T$ and $S$ are temperature and salinity; $R$ is the short wave radiation flux and the data are from ISCCP-FD RadFlux (Zhang et al., 2004); $A_{M}$ and $A_{H}$ are horizontal kinematic viscosity and heat diffusivity, $K_{M}$ and $K_{H}$ are vertical kinematic viscosity and diffusivity, and a second moment Level 2.5 turbulence closure sub-model (Mellor and Yamada, 1982 ) is used to provide these parameters; $T_{x}$ and $T_{y}$ represent the influence of radiation stress induced by wave and can be acquired directly from water wave model, i.e. SWAN. POM uses the mode splitting technique which separates the vertically integrated equations from the vertical structure equations (Eq. (1)). The variables of vertically integrated momentum equations are denoted with an overline, i.e. $\bar{U}, \bar{V}$.

The wave simulation component uses the third generation wave model, SWAN version 40.85 (Booij et al., 1999). The wave spectrum action equilibrium equation with source and sink is solved as follows:

$\frac{\partial N}{\partial t}+\nabla_{\vec{x}} \cdot\left[\left(\vec{c}_{g}+\overrightarrow{\bar{U}}\right) N\right]+\frac{\partial c_{\sigma_{w}} N}{\partial \sigma_{w}}+\frac{\partial c_{\theta} N}{\partial \theta}=\frac{S_{\text {tot }}}{\sigma_{w}}$

in which $N$ is the action density, $\vec{c}_{g}=\underline{\partial \sigma_{w}}$ is the group velocity ( $\vec{k}$ is the wave number vector), $\bar{U}$ is the depth-avekaged current velocity vector, $c_{\sigma_{w}}$ and $c_{\theta}$ are the propagation velocities in spectral space $\left(\sigma_{w}, \theta\right) . S_{\text {tot }}$ is a source/sink term, and contains six sub-terms in a shallow water area:

$S_{\text {tot }}=S_{i n}+S_{n l 3}+S_{n l 4}+S_{d s, w}+S_{d s, b}+S_{d s, b r}$.

These six terms represent wind-induced wave generation, nonlinear wave energy transport induced by three-wave interaction and four-wave interaction, wave dissipation induced by whitecapping, bottom friction and water depth change. The Westhuysen scheme (Van der Westhuysen et al., 2007) is used here, the coefficient Cds2 for determining the rate of whitecapping dissipation is set to $1.8 \times 10^{-5}$, the quadruplet configuration coefficient $\lambda$ in the Discrete Interaction Approximation (DIA) (Hasselmann et al., 1985) of the quadruplet interactions is 0.29 , and other parameters are set to the default configuration. The bottom friction parameter used in the vortex viscosity model is proposed by Grant and Madsen (1979). The surface elevation $\eta$ and the depth-averaged current velocity $(\bar{U}, \bar{V})$ obtained by current simulation component are imported to SWAN to consider the influence of current on water wave.

The topography data from Global Topography V13.1 dataset (Smith and Sandwell, 1997), the temperature and salinity data from the World Ocean Atlas 2001 (WOA 01) dataset (Boyer et al., 2005), the surface wind speed data from Cross-Calibrated Multi-Platform (CCMP) dataset (Atlas et al., 1996), the SST data from OAFlux() and the volume flux through water column surface data from OAFlux (Yu et al., 2008) and 1 Degree Daily (1DD) Precipitation Estimate, Version 1.1 (Huffman et al., 2001) are used in this paper.

At the lateral open boundary, the depth-averaged velocities $(\bar{U}, \bar{V})$ are given according to formula $(\bar{U}, \bar{V})=\sum_{i}^{K 1,01, P 1, Q 1, M 2, S 2, N 2, K 2} f_{i} H_{i} \cos \left(\omega_{i} t+\right.$ $\left.\nu_{i}-g_{i}\right) ; f_{i}, H_{i}, \omega_{i}, v_{i}$, and $g_{i}$ represent the fix factor, amplitude, frequency, tidal initial astronomical angle and phase angle, respectively; $f_{i}$ and $v_{i}$ are calculated using the t_tide harmonic analysis toolbox (Pawlowicz et al., 2002); $H_{i}$ and $g_{i}$ are provided from the global ocean tide model, TPXO 7.2 (Egbert and Erofeeva, 2002); the threedimensional velocities $(U, V)$ and surface elevation $\eta$ are calculated using Orlanski radiation boundary condition(Orlanski, 1976). The temperature and salinity are clamped using the World Ocean Atlas 2001 (WOA 01) (Boyer et al., 2005). Other variables' lateral open boundary conditions of ocean model are set to the default configuration. The lateral open boundary wave parameters for the wave equation are acquired from the larger area wave calculation with non-clamped lateral open boundary using SWAN.

The surface boundary conditions for the temperature and salinity equation are that SST and volume flux through water column surface are clamped. The surface boundary condition for the current momentum equation is expressed as follows:

$$
\left\{\begin{array}{l}
\left.W(x, y, 0, t)\right|_{\sigma=0}=0 \\
\left.\frac{K_{M}}{D}\left(\frac{\partial U}{\partial \sigma}, \frac{\partial V}{\partial \sigma}\right)\right|_{\sigma=0}=-(<w u(0)>,<w v(0)>) \\
(<w u(0)>,<w v(0)>)=\rho_{a} C_{D}\left(\left|u_{10}\right| u_{10},\left|v_{10}\right| v_{10}\right)
\end{array}\right.
$$

in which $w u(0)$ and $w v(0)$ represent the latitudinal and longitudinal surface wind stress components, respectively, and are the input values for the surface open boundary of the momentum equation of the three-dimensional ocean model. In Eq. (4), $\rho_{a}$ is the air density, $\left(u_{10}, v_{10}\right)$ is the wind speed at $10 \mathrm{~m}$ above the sea level, and $C_{D}$ is the drag coefficient. The influence of the wave on the surface wind stress can be acquired by changing the formula for the drag coefficient $C_{D}$. The modified formula for the drag coefficient is (Donelan et al., 1993):

$C_{D}=\left(\frac{\kappa}{\ln 10-\ln Z_{0}}\right)^{2}$

in which $\kappa$ is the von Karman constant, the surface roughness parameter is $Z_{0}=3.7 \times 10^{-5} \frac{\left(u_{10}^{2}+v_{10}^{2}\right)}{g}\left(\frac{\sqrt{u_{10}^{2}+v_{10}^{2}}}{C_{p}}\right)^{0.9}$; the wave speed corresponding to the peak frequency $\omega_{p}$ is $C_{p}=\frac{\omega_{p}}{k_{p}} ; k_{p}$ can be iteratively calculated using the wave dispersion relationship $\omega_{p}{ }^{2}=\left(g k_{p}\right) \tanh \left(k_{p} D\right), \omega_{p}$ can be calculated in SWAN; $\frac{C_{p}}{\sqrt{u_{10}^{2}+v_{10}^{2}}}$ is the wave age. When considering wave-current coupling, the drag coefficient not only relates to wind speed but is also closely related to the water depth and peak period.

The bottom boundary condition for the current momentum is given as follows:

$\left\{\begin{array}{l}\left.W(x, y,-1, t)\right|_{\sigma=-1}=0 \\ \left.\frac{\rho K_{M}}{D}\left(\frac{\partial U}{\partial \sigma}, \frac{\partial V}{\partial \sigma}\right)\right|_{\sigma=-1}=\left(\tau_{b x}, \tau_{b y}\right)\end{array}\right.$

in which $\tau_{b x}$ and $\tau_{b y}$ are the latitudinal and longitudinal components of the bottom shear stress $\vec{\tau}_{b}$, respectively, and follow the rule:

$$
\vec{\tau}_{b}=\left(\tau_{b x}, \tau_{b y}\right)=\rho\left(U_{*}^{2}, V_{*}^{2}\right)=\left.\frac{1}{2} \rho f_{c}\left[U^{2}+V^{2}\right]^{1 / 2}(U, V)\right|_{\sigma=-1}
$$

where $U_{*}$ and $V_{*}$ are bottom friction velocities; $f_{c}$ is the bottom friction coefficient, and the impact of the wave on the bottom shear stress can be added by changing the bottom friction parameter:

$f_{c}=2\left[\frac{0.4}{\ln \left(30 z_{r} / k_{b c}\right)}\right]^{2}$

where $z_{r}$ is the reference height and is defined as the distance to the sea bed of the centre of the bottom grid cell, and $k_{b c}$ is the apparent bottom roughness under the interaction of waves and current used in the SWAN model. Grant and Madsen (1979) proposed the formula:

$k_{b c}=k_{b}\left[24 \frac{U_{* c w}}{U_{w}} \frac{A_{b}}{k_{b}}\right]^{\beta}$

in which $k_{b}$ is the physical bottom roughness and is set as $0.03 \mathrm{~m}$ here; $A_{b}=\frac{U_{w}}{\omega}$ is the near bottom excursion amplitude, $U_{w}$ is the maximum near-bottom wave orbital velocity, $\omega$ is the near-bottom wave frequency and is calculated using the SWAN model; $U_{* c W}=$ $\sqrt{U_{* c}^{2}+U_{* w}^{2}+2 U_{* c} U_{* w} \cos \phi_{c}}$ is the combined current-wave friction 
velocity, $\phi_{c}$ is the angle between the wave propagation and the current (Jing and Ridd, 1996); $U_{* c}=\sqrt{\frac{1}{2} f_{c} U_{c}^{2}}$ is the current friction velocity, $\vec{U}_{c}=$ $\left.(\vec{U}+\vec{V})\right|_{z=z_{r}}$ is the current velocity at the reference height $z_{r} ; \beta=1-\frac{U_{* c}}{U_{* \mathrm{c} w}}$ $U_{* w}=\sqrt{\frac{1}{2} f_{w} U_{w}^{2}}$ is the wave friction velocity, and $f_{w}$ is the wave friction factor and is calculated using the empirical formula proposed by Signell et al. (1990):

$f_{w}= \begin{cases}0.13\left(k_{b} / A_{b}\right)^{0.4} & k_{b} / A_{b}<0.08 \\ 0.23\left(k_{b} / A_{b}\right)^{0.62} & 0.08<k_{b} / A_{b}<1.00 \\ 0.23 & k_{b} / A_{b}>1.00\end{cases}$

Theoretically, $f_{c}$ must be solved using an iterative method. Davies and Lawrence (1994) found a scheme that can reduce the number of iterations while maintaining the accuracy. Additionally, $k_{b c}$ is initially set to be the same as $k_{b}$, and is subsequently updated with $f_{c}$ in every calculation.

The process of data transfer during coupling of the current and wave is shown in Fig. 2. The POM and SWAN models run in different processes and exchange data once an hour. The data exchange is facilitated by MPI programming. It must be mentioned that both models use the same computational grid during coupling. To balance the computation load among different processes, the ratio of the number of processes used by POM and SWAN is approximately 1:7.

\subsection{Grid-nesting design}

Three points must be noted: 1 ) the area of field $S$ is only $7 \mathrm{~km}^{2}$ and is located in an open sea area, and the elevation and velocity at the lateral boundary are difficult to acquire accurately. To decrease error, the length of the lateral open boundary is chosen as short as possible, and hence, the lateral boundary is set to the Qiongzhou Strait and south mouth of Beibu Gulf; 2) the physical duration of sand wave simulation must be longer than 1 year; 3 ) the sand wave is located on the sand ridge back and grooves, and to resolve the sand ridge and reflect its influence on current, the number of grid points must be sufficient and the resolution must be smaller than $330 \mathrm{~m}$. In other words, the simulation of the sand wave migration in field $\mathrm{S}$ must meet the requirements for space, time, and accuracy. If direct simulation is used, the computational efficiency will be unacceptable. Hence, we propose the use of the grid nesting method.

The so-called grid nesting method consists of a smaller domain nested inside a larger domain. Coarser grids are used in the larger domain, and a finer grid is used in the focus area. The boundary condition of the smaller area is interpolated from the computational result of the larger domain. To decrease the error produced from the interpolation during grid nesting, the degree of overlap of both grids must be enhanced. Hence, we design the following rules. In the vertical direction, the vertical layer scheme remains the same between the larger and smaller zones and are as in the work of Jiang et al. (2014) where the vertical grids are denser near the bottom to make sure the bottom is well resolved; and in the horizontal direction, the horizontal grid spacing of the smaller zone is $1 / 3$ that of the larger zone. With this arrangement, the number of overlapping grid points in the entire area is the largest.

In this work, two stages of grid nesting are used, and the resolution of the grid is increased from $1800 \mathrm{~m}$ to $600 \mathrm{~m}$, and finally up to approximately $200 \mathrm{~m}$. The computational domains and flow chart are shown in Fig. 3 . The temperature, salinity and velocity profiles at the lateral open boundary of the second- and third-level computations are clamped with the results from coarser grid calculations. The depth-averaged fluxes are clamped along the lateral open boundary with the radiation elevation condition instead of that the depth-averaged velocities are clamped; this approach can adjust the velocities automatically with the elevation along the open boundary and keep mass conservation during the grid nesting procedure.

\subsection{Verification of wave-current coupling module}

The simulated tidal constants of K1, 01 and M2 constituents of 24 tide stations distributed dispersedly in this gulf have already been verified with measurements in Jiang and Lin (2011), and the circulation model is proved to be able to describe the tide characteristics of this gulf.

Beside this, observation data are retrieved from a survey run by scientists from the Institute of Oceanography at the Chinese Academy of Sciences. The dataset spans from 2 o'clock on Aug. 21st, 2006 to 2 o'clock on Jan. 22th, 2007 and is located to the west of field S with coordinates $18^{\circ} 53.765^{\prime} \mathrm{N}, 108^{\circ} 15.614^{\prime} \mathrm{E}$. The velocities from sea level to $4 \mathrm{~m}$ above the seabed, sea wave parameters, elevation, and seawater temperature near the sensor located approximately $1.8 \mathrm{~m}$ above the seabed are recorded with a time interval of $3 \mathrm{~h}$ (Ma et al., 2011). It is found that the longitudinal velocity is four times as large as the latitudinal velocity, and the main direction of the current in the area is longitudinal.

The wave-current coupling model is used to simulate the threedimensional ocean current field of the corresponding time range. The resulting elevation, longitudinal velocity at specific depth, bottom temperature and water wave features are plotted in Fig. 4 together with the measured data. The figure shows that the simulated results of these physical quantities are consistent with the measured ones. It is indicated that the treatment of the input data and boundary condition of the model used in this paper are suitable. Of special note is the ability of this model to capture the long-term trend of the near-bottom sea temperature (Fig. 4d) which indicates that solving the temperature and salinity equation and setting the clamped sea surface temperature (SST) as variable with time at the surface open boundary is a suitable treatment. In summary, the current features in the sand wave area can be captured accurately with this model which enables the following process.

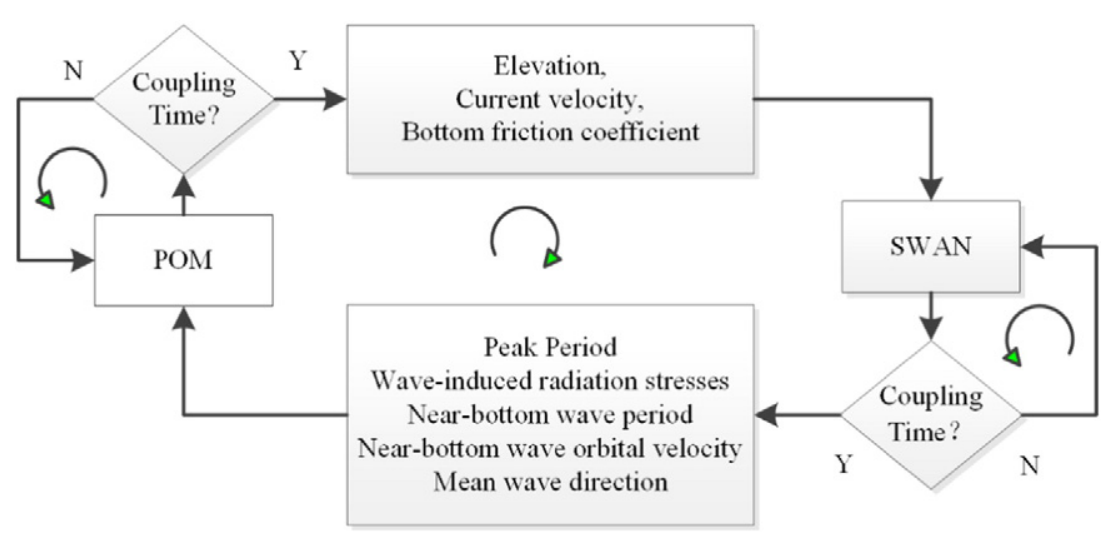

Fig. 2. Data exchange route for wave current coupling. 


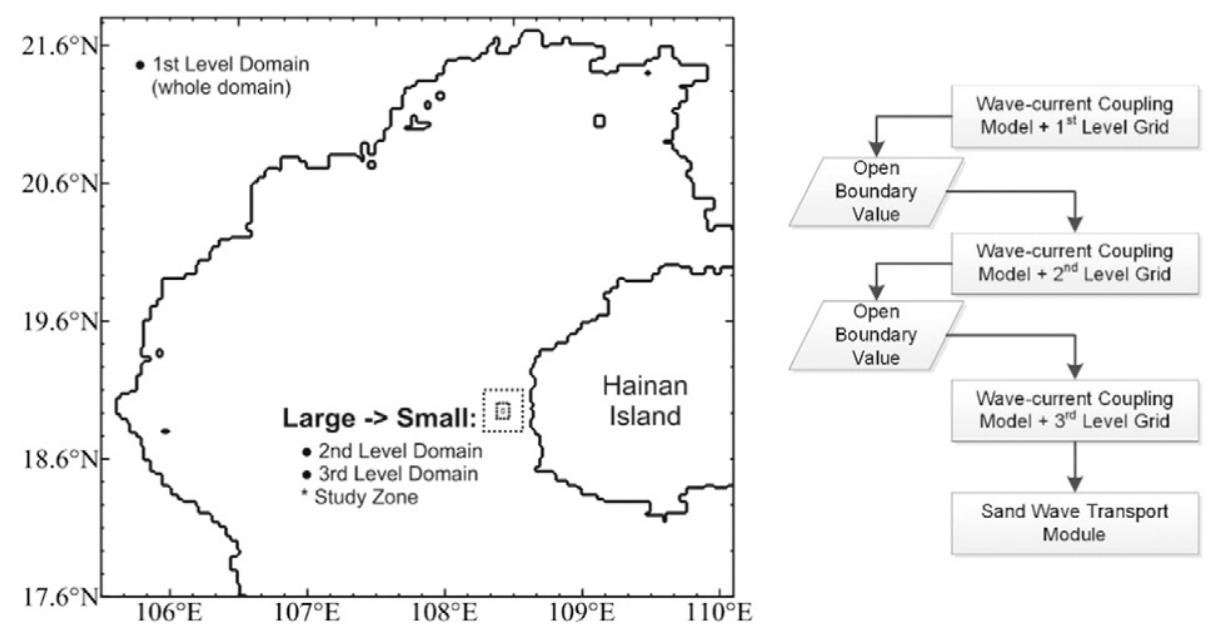

Fig. 3. Computational domain of grid nesting and the computation flow chart. a) Schematic figure of all-level computational grid and b) computational flow chart.

\section{Sand wave migration simulation}

\subsection{Bedload transport module}

Previous research showed that sand wave migration occurs primarily in the form of bedload. Especially in the offshore area impacted by the tide, the bedload plays an important role in sediment transport (Németh et al., 2004). Considering that the median sand diameter is $0.34 \mathrm{~mm}$ in field $\mathrm{S}$ and the Rouse number indicates the transport mode is bedload transport, hence bedload transport is considered in this paper. The modified Meyer-Peter-Müller (Meyer-Peter and Müller, 1948) formula suitable for reciprocating flow is used to calculate the bedload transport $\vec{q}$ :

$\vec{q}=\left\{\begin{array}{lc}8 \frac{\vec{\tau}_{b}}{\left|\vec{\tau}_{b}\right|}\left(\frac{\left|\vec{\tau}_{b}\right|}{\rho g(s-1) d}-\Theta_{C}\right)^{3 / 2} \sqrt{(s-1) g d^{3}} & \frac{\left|\vec{\tau}_{b}\right|}{\rho g(s-1) d}>\Theta_{C} \\ 0 & \frac{\left|\vec{\tau}_{b}\right|}{\rho g(s-1) d} \leq \Theta_{C}\end{array}\right.$

where $s=\rho_{s} / \rho$ is the density ratio of sediment to seawater, $\Theta_{c}$ is the dimensionless critical shear number and is commonly set to 0.047 , and $d$ is the median sand diameter. The water depth of the grid points in the current computation with a horizontal resolution of $200 \mathrm{~m}$ is set to the mean value of the local area in the wave-current coupling module, and the bedload transport $q\left(\bar{h}_{g}\right)$ obtained with Eq. (11) is the value at the mean depth. The bedload transport $q(\bar{h})$ at the mean depth of the sand wave with a wavelength of about $30 \mathrm{~m}$ can be obtained by interpolation of $q\left(\bar{h}_{g}\right)$.

Comparing the sand wave profiles in 2007 and 2009 (Fig. 5), the shapes of the sand waves only have a small change, and the former and latter positions of a sand wave crest can be clearly identified. Considering that the focus of this paper is the migration direction, it is reasonable to assume that the shape of the sand wave doesn't change during the migration process, and the movement speed is $\mathrm{C}$; therefore, according to the mass conservation law, the difference in bedload transport between arbitrary depth $h$ and the groove $h_{T}$ is (Jiang et al., 2014):

$q(h)-q\left(h_{T}\right)=\int_{h_{T}}^{h} C d y=C\left(h-h_{T}\right)$.

Assuming the bedload transport at the groove is quite small and can be neglected, the sand wave migration speed $\mathrm{C}$ can be calculated according to the bedload transport $q(\bar{h})$ at the mean depth of the sand wave.

$C=\frac{q(\bar{h})}{\bar{h}-h_{T}}$

Thus, the bedload transport at an arbitrary depth $h$ can be calculated:

$q(h)=q(\bar{h}) \frac{h-h_{T}}{\bar{h}-h_{T}}$.

Next, the bedload transport is substituted into the mass conservation equation for sand transport,

$\frac{\partial h}{\partial t}+\nabla \cdot \vec{q}=0$

and the sand wave migration can be calculated.

\subsection{Comparative analysis of simulated and observed results}

Sand wave migration from Oct. 2007 to Sep. 2009 was simulated. Several profiles referred to as W1-2, C1-2, and E1-3 were selected, and the positions of these profiles are shown in Fig. 1, located in the western, central and eastern regions of the sand wave field, respectively. The results are shown in Fig. 5. The horizontal axis represents the distance to the beginning of the profile, and the beginning of the profile is the point with the largest latitude in the profile, which means that the positive direction of horizontal axis indicates southwards. The green solid line indicates the measured result in Sep. 2009, the black solid line denotes the simulated bedform in Sep. 2009, and the measured results in Oct. 2007 are plotted with green dashed line.

It can be concluded from Fig. 5 that the simulated results of profiles $\mathrm{C} 1$ and $\mathrm{E} 3$ are consistent with the measured ones; the migration speed is larger than the measured speed in profiles W1, W2 and C2; the migration speed is less than the observation in profile E1 and E2; and all the simulation results and the observations have the same order of magnitude. The discrepancy may be caused by the treatment that all the sand waves have the same sediment diameter because only one site observation in these area has been done and the result are used here. Another possible reason is that some sand wave shapes have a small change during migration. It is worth noting that all of the simulated migration directions are consistent with the observations. We take the angle between the migration direction 


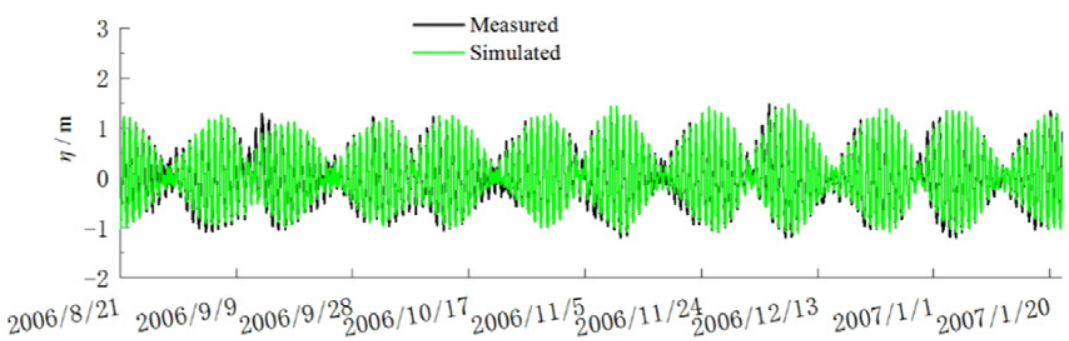

a) Elevation

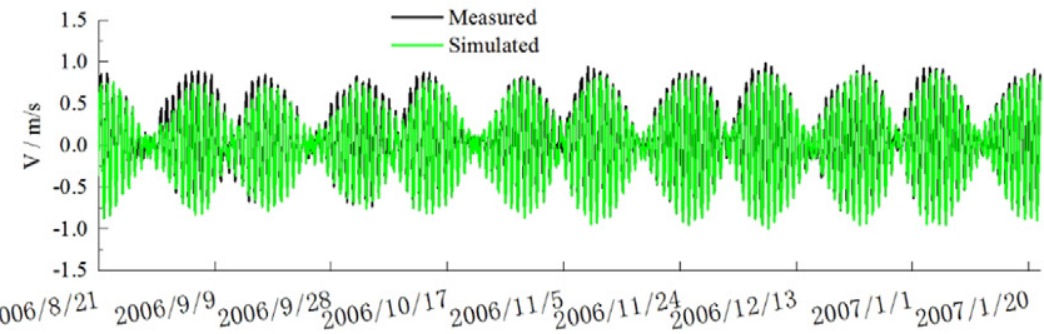

b) Velocity $V$ at a depth of $31 \mathrm{~m}$

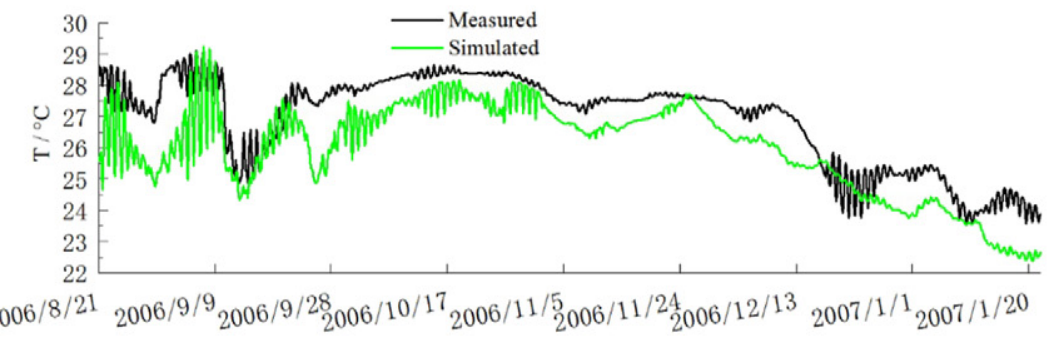

c) Temperature at a depth of $34 \mathrm{~m}$

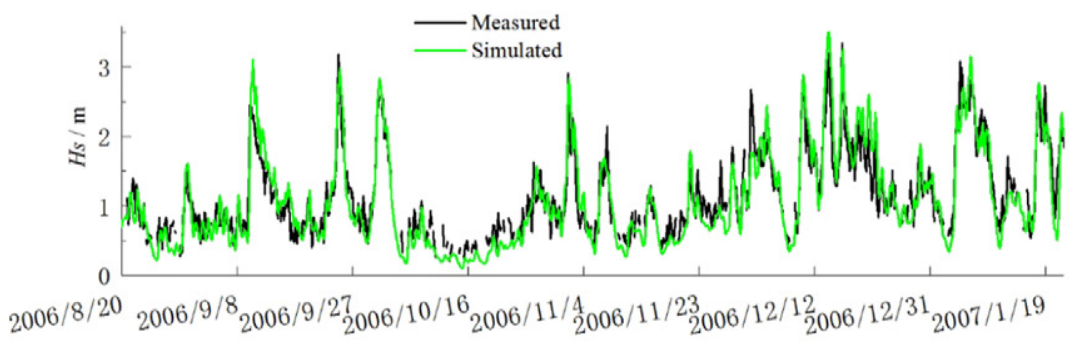

d) Significant wave height

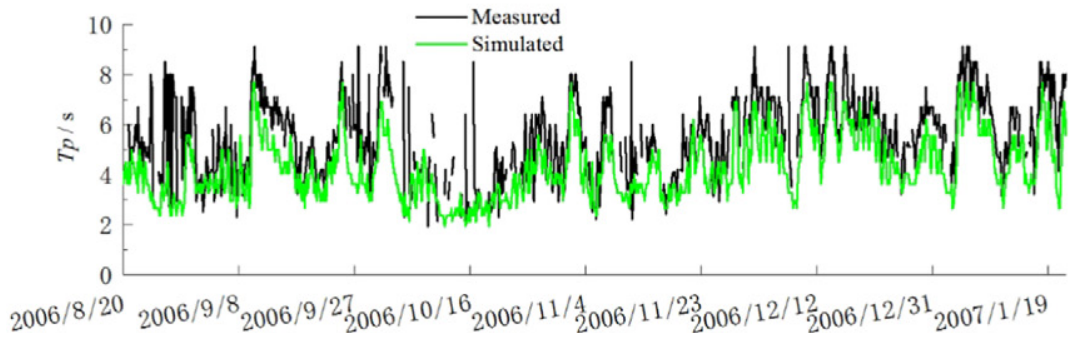

e) Wave peak period

Fig. 4. Comparison of elevation, velocity, temperature, and wave parameters between simulated and measured data. 


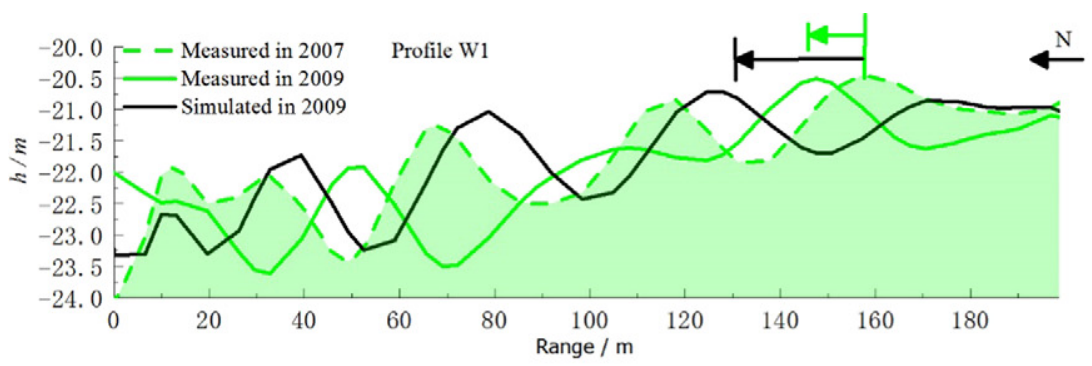

a) Profile W1

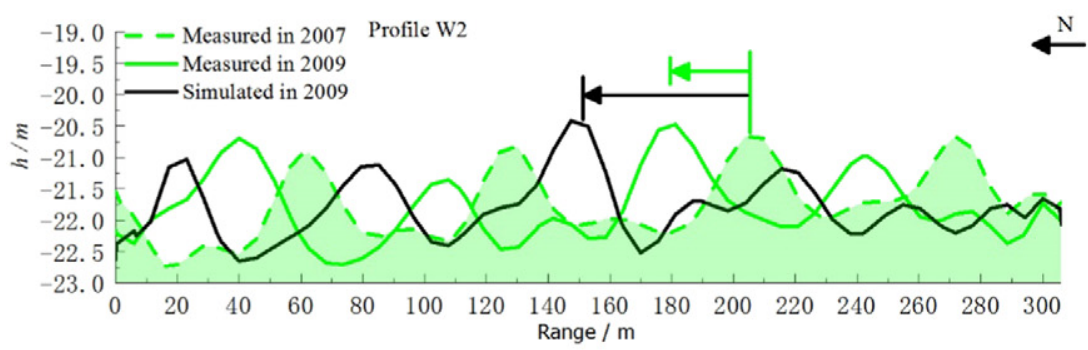

b) Profile W2

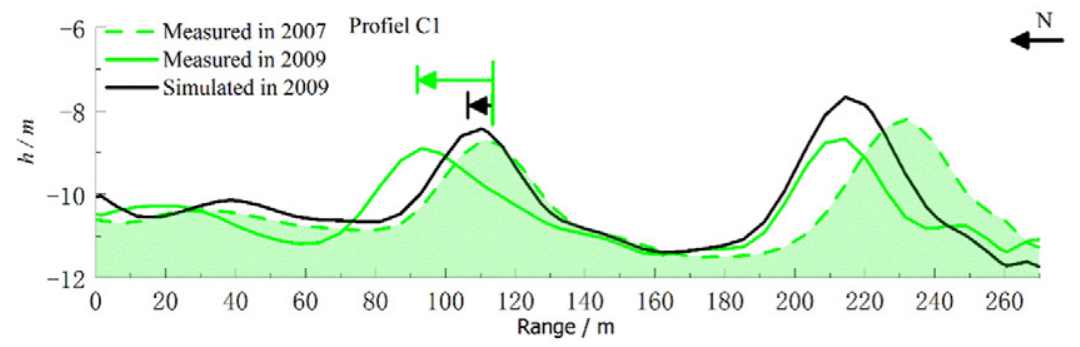

c) Profile C1

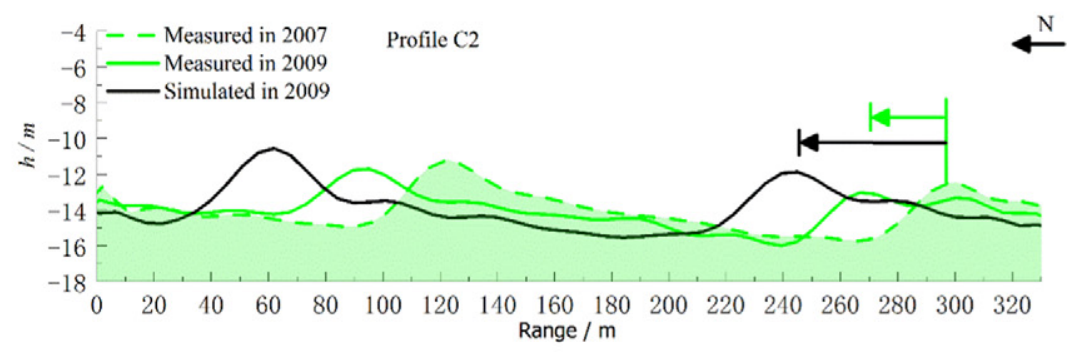

d) Profile C2

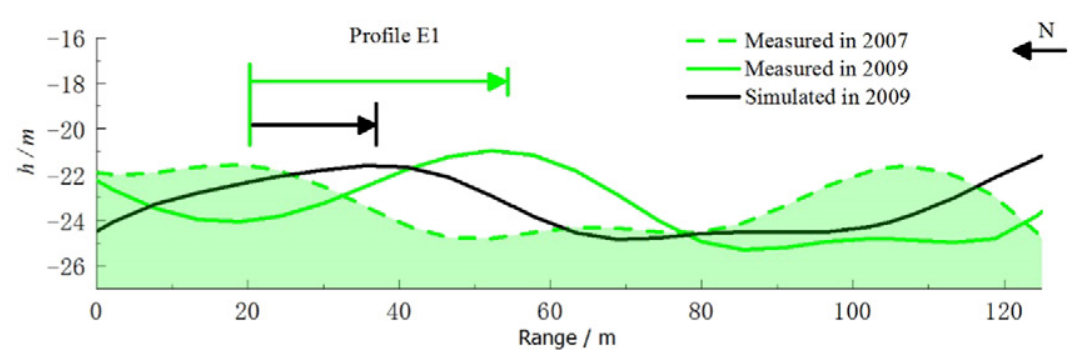

e) Profile E1

Fig. 5. Comparison of simulated and measured results of sand wave migration in the profiles from 2007 to 2009. 

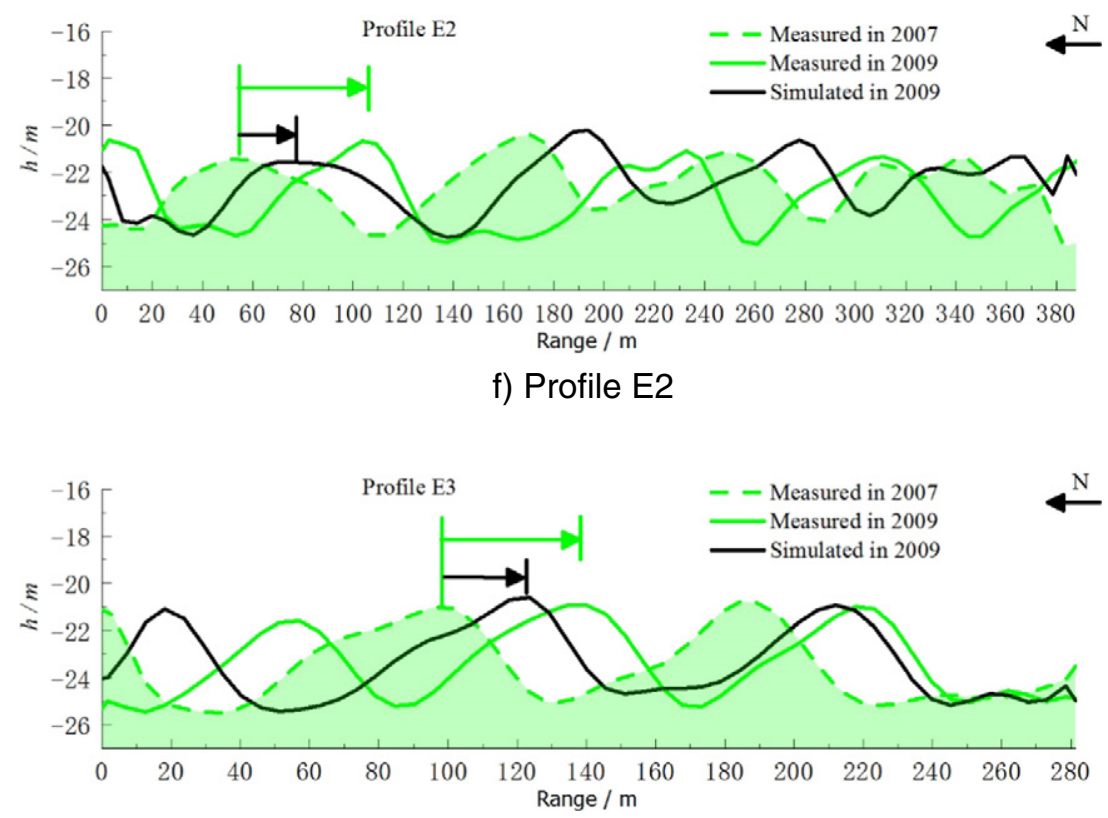

g) Profile E3

Fig. 5 (continued).

and the direction of latitude as the physical quantity for investigation, and observe that the angle is less than $30^{\circ}$. Sand waves in the western and middle portions of the sand wave migrate northwards, and sand waves in the eastern portion migrate southwards, presenting a clockwise bilateral reverse migration trend. The result is listed in Table 1 , and it is obvious that the simulated direction is notably close to the observed direction.

The computational result shows that the combination of the wavecurrent coupling model and the sand transport model proposed in this paper are able to simulate the bilateral reverse migration feature of small-scale sand waves of the same group.

\section{Discussion of the mechanism of sand wave bilateral reverse migration}

Based on the successful reproduction of sand wave bilateral reverse migration, this section primarily discloses its mechanism. Three representative profiles, W1, C2 and E3 are chosen for further analysis. Bottom friction velocity is chosen as the inspecting physical quantity of the analysis and is considered as a combination of three parts, i.e. tidal constituents, steady (residual) component and short-term fluctuation, through harmonic analysis technique. A method based on bedload transport calculation is proposed to determine the contributions of the above three parts to migration. How the bilateral reverse migration happens is illustrated with the above analysis framework.

Table 1

Comparison of simulated sand wave migration direction with observation in every profile

\begin{tabular}{lcc}
\hline Profile & Measured migration direction $\left({ }^{\circ}\right)$ & Simulated migration direction $\left({ }^{\circ}\right)$ \\
\hline W1 & 104 & 114 \\
W2 & 103 & 100 \\
C1 & 88 & 82 \\
C2 & 82 & 83 \\
E1 & -104 & -109 \\
E2 & -98 & -99 \\
E3 & -95 & -97 \\
\hline
\end{tabular}

4.1. Harmonic analysis of the bottom friction velocities in the sand wave field

Based on the assumption that the sand wave shape is unchanged during migration, the direction of sand wave migration can be quickly judged. Because the sand wave migration speed $C$ is proportional to the bedload transport $q(\bar{h})$ at the mean elevation of the sand waves, it is possible to calculate the bedload transport $q(\bar{h})$ at the mean elevation of sand waves and sum it over time to determine the sand wave migration direction. Bottom friction velocity relates to bedload transport more directly than water elevation, depth-averaged velocity and near bottom velocity, therefore it is chosen as the inspecting physical quantity and its difference between different profiles needs to be compared. Considering that the difference of the sand wave migration directions in different profiles of the area primarily along the direction of longitude, and the amplitude of the longitudinal component is larger than that of the latitudinal component, hence the longitudinal component is analysed further on.

In open sea area such as the sand wave area, the bottom friction velocity varies with time and it's hard to describe the differences in two profiles. Like water elevation, the bottom friction velocity can be considered as a combination of three parts: tidal constituents, steady (residual) component and short-term fluctuation. The simulated longitudinal bottom friction velocities $V_{*}$ of the three representative profiles (i.e., W1, C2 and E3) in the study area are harmonically analysed using t_tide matlab toolbox (Pawlowicz et al., 2002), and the tidal constants of 68 tide constituents and the steady (residual) component can be acquired. The longitudinal synthesised bottom friction velocity $\tilde{V}_{*}$ is defined as the sum of all the 68 main tidal constituents and the residual velocity

$\tilde{V}_{* j}=\sum_{i=1}^{68} f_{i}^{j} H_{i}^{j} \cos \left(\omega_{i} t+\nu_{i}^{j}-g_{i}^{j}\right)+v_{0}^{j}, j=W 1, C 2, E 3$

in which $H_{i}^{j}$ and $g_{i}^{j}$ represent the amplitude and phase lag of the $i$-th tidal constituent in the $j$ profile, respectively; $f_{i}^{j}, v_{i}^{j}$ represent the fix factor, tidal initial astronomical angle of the $i$-th tidal constituent in the $j$ profile, and the values are very close in such a small area; $v_{0}^{j}$ denotes the residual velocity in the $j$ profile. The discrepancies between $\tilde{V}_{*}$ and $V_{*}$ are short-term fluctuations which are due to the influence of short- 


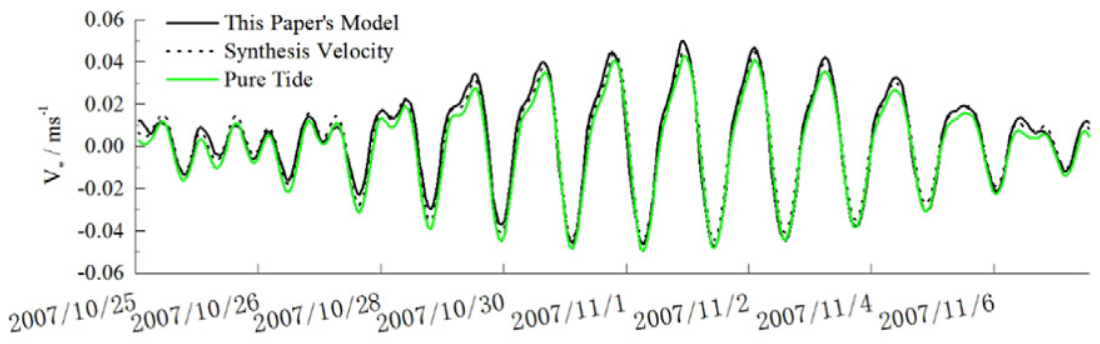

a) Profile W1

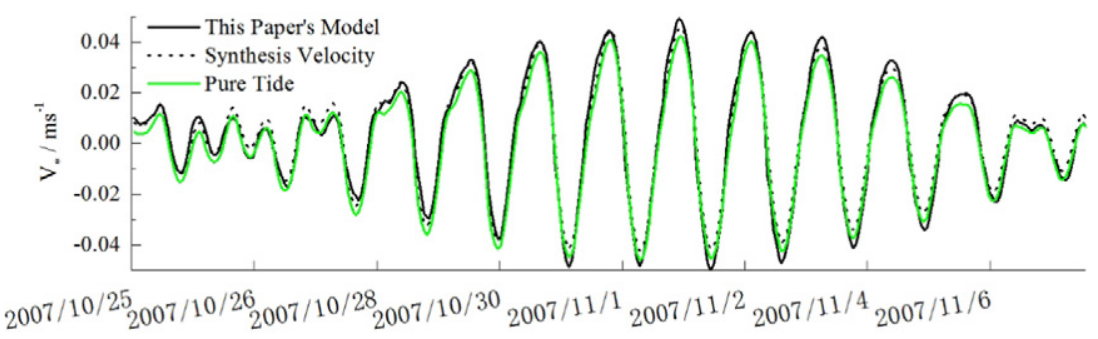

b) Profile $\mathrm{C} 2$

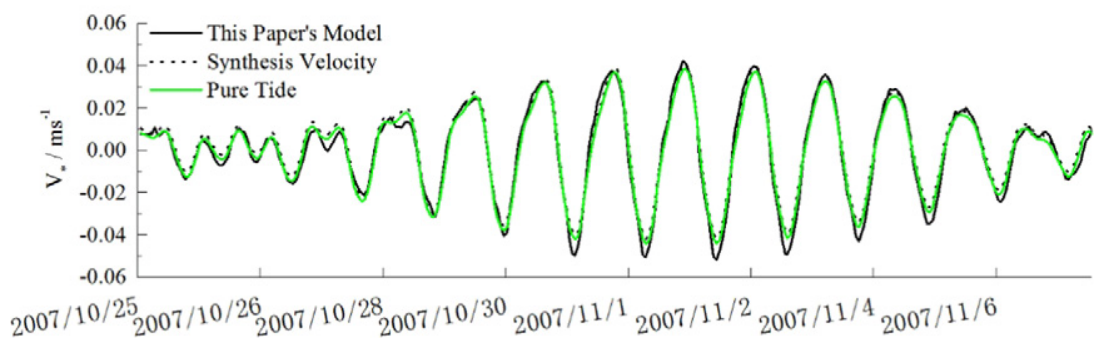

c) Profile E3

Fig. 6. Velocity variation with time under three conditions.

term phenomenon and other factors. Fig. 6 shows the simulated nearbottom friction velocity $V_{*}$ (denoted with a black solid line) and the synthesised velocity $\tilde{V}_{*}$ (denoted with a black dashed line) variation with time in the three profiles at the beginning time range (approximately $2 \%$ of the total calculation time range or 14 days out of 727 days). The solid green line denotes the so-called "pure tidal" velocity where the residual velocity in $V_{*}$ is set to zero. It can be concluded that the phase of the synthesised velocity is consistent with that of the actual velocity, with some amplitude offsets at certain occurring times. These offsets between the result from the harmonic analysis and the actual velocity exist universally and are caused by short-term meteorological factors and seasonal variation anomalies, i.e., storm surge, monsoon anomalies, etc. (Chen et al., 2009).

In order to quantify the discrepancies between $\tilde{V}_{*}$ and $V_{*}$, the parameter $\lambda$ which represents the ratio of variances between $\tilde{V}_{*}$ and $V_{*}$ is defined as:

$\lambda_{V_{*}}=\tilde{\sigma}_{V_{*}}^{2} / \sigma_{V_{*}}^{2}$

in which:

$\tilde{\sigma}^{2} V_{*}=\frac{\sum_{i=1}^{N}\left(\tilde{V}_{* i}-\tilde{V}_{*}\right)^{2}}{N}, \sigma_{V_{*}}^{2}=\frac{\sum_{i=1}^{N}\left(V_{* i}-\bar{V}_{*}\right)^{2}}{N}$ where $\mathrm{N}$ is the total number of velocity time series data points, the variables with a overline are time average value. The results of three profiles (i.e., W1, C2 and E3) are listed in Table 2. The values are close to $100 \%$ and it can be concluded that $\tilde{V}_{*}$ is consistent with $V_{*}$ as a whole, which means that the tidal components and the residual velocity plays an absolute dominating role.

\subsection{Tidal constituent constants and residual velocity characteristics}

Moreover, the synthesised velocity can be divided into two components. One component is the combination of many tidal constituents, and another is the residual velocity. First, the differences in the tidal constituent constants are investigated. The differences in the tidal constituent constants between profile $\mathrm{W} 1, \mathrm{E} 3$ and $\mathrm{C} 2$ are defined as $\Delta H_{i}^{W 1-C 2}, \Delta H_{i}^{E 3-C 2}, \Delta g_{i}^{W 1-C 2}$ and $\Delta g_{i}^{E 3-C 2}$ :

$$
\begin{aligned}
& \Delta H_{i}^{W 1-C 2}=H_{i}^{W 1}-H_{i}^{C 2} \\
& \Delta H_{i}^{E 3-C 2}=H_{i}^{E 3}-H_{i}^{C 2} \\
& \Delta g_{i}^{W 1-C 2}=g_{i}^{W 1}-g_{i}^{C 2} \\
& \Delta g_{i}^{E 3-C 2}=g_{i}^{E 3}-g_{i}^{C 2} .
\end{aligned}
$$

The results of the six strongest constituents are listed in Table 3. It is obvious that the phase angles of $\mathrm{W} 1, \mathrm{E} 3$, and $\mathrm{C} 2$ are quite similar; the difference does not exceed $10^{\circ}$. It can be concluded that in such as small sea area with a width of $1 \mathrm{~km}$, the phase variation of main tide 
Table 2

Comparison of velocity covariance in the three profiles.

\begin{tabular}{ll}
\hline Profile & $\lambda_{V .}$ \\
\hline W1 & $97.4 \%$ \\
C2 & $97.8 \%$ \\
E3 & $96.4 \%$ \\
\hline
\end{tabular}

constituents is small. Considering the amplitude differences relative to profile $\mathrm{C} 2$, only the $\mathrm{M} 2$ constituent's amplitude difference is relatively larger in profile $\mathrm{W} 1$, and the other differences of the $\mathrm{K} 1, \mathrm{O} 1$ and $\mathrm{M} 2$ constituents are nearly equal.

Second, the residual velocity feature is investigated, and the residual velocity field is shown in Fig. 7. The residual velocity is directed primarily northward, and only a branch of reverse residual velocity exists in the upper right region of the central sand ridge. These features relate closely to the surrounding topography of the sand wave area. From the background colour map of Fig. 7, it can be found that the sand wave area (denoted with a dashed rectangle) is located on a large north-south sand ridge, and there exists another northwest-southeast small sand ridge to the right of this sand ridge. A ridge fillet is located between the sand ridges with a wedge shape that is wider in the south and narrower in the north. The flood direction of the entire large area is from south to north. The sea flow moves counter-clockwise in the wedge-shape ridge fillet, and the flow counter to the main stream appears in the north region of the wedge area.

Field S (denoted with a dashed rectangle) is located in the centre of the sand ridge, and at the middle of the intersection area of the main stream and counter stream. The residual velocity directions in the three profiles of W1, C2 and E3 are all northward. Profile W1 at the west of the sand ridge and $\mathrm{C} 2$ on the ridge back are influenced less by the counter stream, and the sand wave migration direction is consistent with the residual velocity direction. Profile E3 is influenced much more by the counter stream. Although the residual velocity's direction is consistent with the main stream, the residual velocity's amplitude here is an order of magnitude smaller than those of the other two profiles, and the sand wave migration is opposite to the residual velocity's direction.

\subsection{Bedload transport analysis}

As mentioned above, we can calculate the bedload transport $q(\bar{h})$ and its summation over time $\Sigma_{q(\bar{h})}$ under simulated velocity $V_{*}$ and synthesised velocity $\tilde{V}_{*}$ to determine the sand wave migration direction, and the results are plotted in Fig. 8. The upper figure shows the bedload transport, and the lower figure indicates the bedload

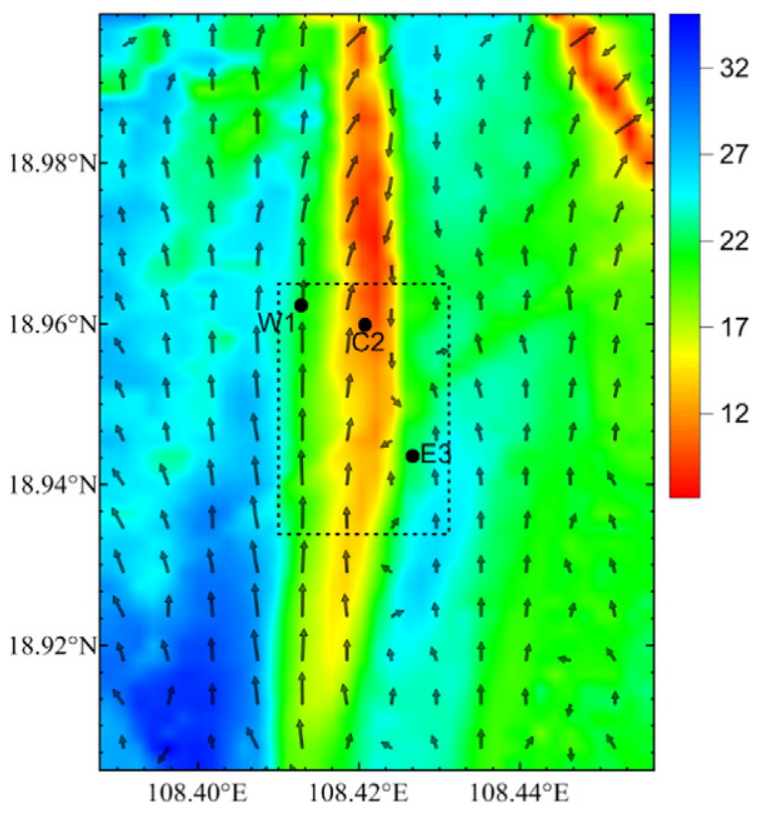

Fig. 7. Surrounding topography and residual velocity field of field S.

transport summation with time. The black solid line or black solid line with filled circles indicates the results under simulated velocity. The dashed line or black solid line with empty circle indicates the results under synthesised velocity. The bedload transport differences between the above two conditions are large at certain moments. When considering the bedload transport summation, it can be observed that under both conditions that the overall trends are consistent, and the values are similar, which indicates that the short-term meteorological factors and season variation anomalies have little influence on the long-term trend of sand wave migration. Hence, the long-term trend of sand wave migration can be determined after the synthesised velocity or tidal constituents and residual velocity are obtained.

From the bedload transport summation of the three profiles shown in Fig. 8, it can be observed that both profiles W1 and C2 are northward, whereas profile E3 is opposite to these two profiles. To analyse the reason for these difference, we calculate the velocity, bedload transport, and its summation over time in the three profiles under the condition of pure tidal influence, where in $V_{*}$ the residual velocity is set to zero. The velocity time series is plotted in Fig. 6 and denoted with a green dashed line for easy comparison. The velocity is directed wholly northward in contrast to that under the synthesised condition in which the residual velocity is northward.

Table 3

Harmonic analysis results of the near-bottom longitudinal velocities in the three profiles

\begin{tabular}{|c|c|c|c|c|c|c|c|c|c|c|}
\hline \multirow[t]{2}{*}{ Tide const. } & \multicolumn{2}{|l|}{ W1 } & \multicolumn{2}{|l|}{$\mathrm{C} 2$} & \multicolumn{2}{|l|}{ E3 } & \multicolumn{2}{|l|}{ W1-C2 } & \multicolumn{2}{|l|}{ E3-C2 } \\
\hline & $\begin{array}{l}H_{i} \\
(\mathrm{~cm} / \mathrm{s})\end{array}$ & $\begin{array}{l}g_{i} \\
\left({ }^{\circ}\right)\end{array}$ & $\begin{array}{l}H_{i} \\
(\mathrm{~cm} / \mathrm{s})\end{array}$ & $\begin{array}{l}g_{i} \\
\left({ }^{\circ}\right)\end{array}$ & $\begin{array}{l}H_{i} \\
(\mathrm{~cm} / \mathrm{s})\end{array}$ & $\begin{array}{l}g_{i} \\
\left({ }^{\circ}\right)\end{array}$ & $\begin{array}{l}\Delta H_{i} \\
(\mathrm{~cm} / \mathrm{s})\end{array}$ & $\begin{array}{l}\Delta g_{i} \\
\left({ }^{\circ}\right)\end{array}$ & $\begin{array}{l}\Delta H_{i} \\
(\mathrm{~cm} / \mathrm{s})\end{array}$ & $\begin{array}{l}\Delta g_{i} \\
\left(^{\circ}\right)\end{array}$ \\
\hline K1 & 1.81 & 222 & 1.86 & 227 & 1.69 & 218 & -0.05 & -5 & -0.17 & -9 \\
\hline 01 & 1.70 & 163 & 1.73 & 168 & 1.56 & 159 & -0.03 & -5 & -0.17 & -9 \\
\hline M2 & 0.84 & 154 & 0.65 & 157 & 0.48 & 152 & 0.19 & -3 & -0.17 & -5 \\
\hline P1 & 0.50 & 218 & 0.48 & 227 & 0.47 & 217 & 0.02 & -9 & -0.01 & -10 \\
\hline Q1 & 0.36 & 129 & 0.37 & 132 & 0.34 & 125 & -0.01 & -3 & -0.03 & -7 \\
\hline S2 & 0.23 & 199 & 0.20 & 206 & 0.16 & 204 & 0.03 & -7 & -0.04 & -2 \\
\hline$v_{0}$ & 0.36 & & 0.33 & & 0.01 & & 0.03 & & -0.31 & \\
\hline Migration & \multicolumn{2}{|c|}{ Northwards } & \multicolumn{2}{|c|}{ Northwards } & \multicolumn{4}{|c|}{ Southwards } & & \\
\hline
\end{tabular}




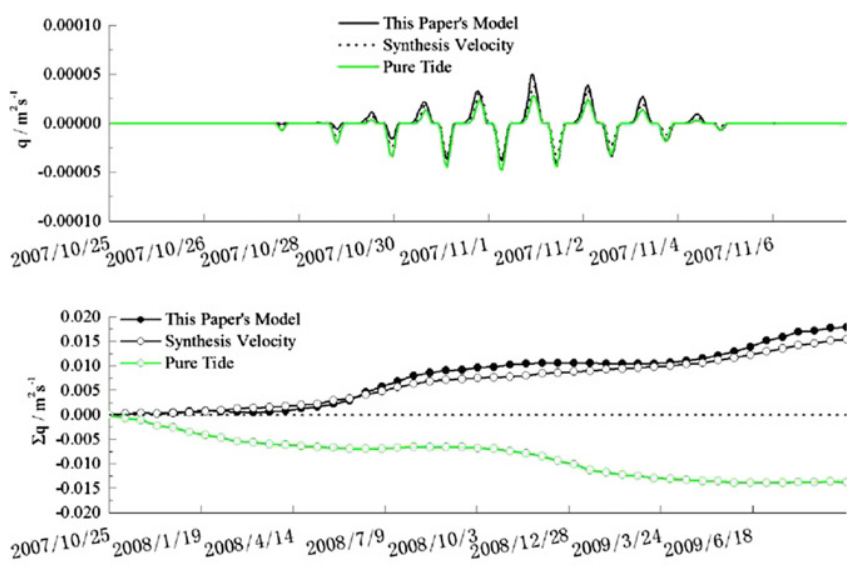

a) Profile W1
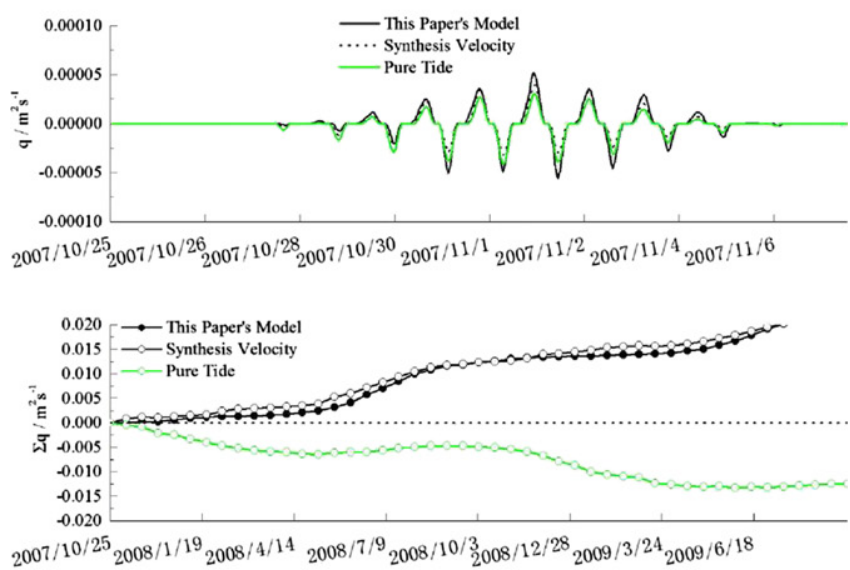

\section{b) Profile C2}
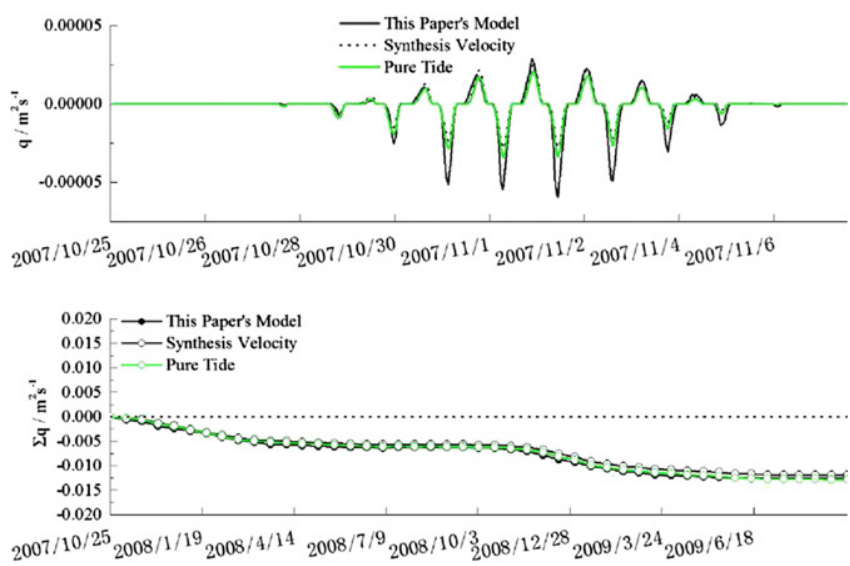

\section{c) Profile E3}

Fig. 8. Time series of bedload transport and its summation over time under three conditions.
It also can be found that under pure tidal conditions, sand waves in all three profiles migrate towards the negative Y-axis, and the migration distances are quite similar, which means that the sand waves migrate southwards. In this situation, although the residual velocity is zero, because of the nonlinear relationship between bedload transport and velocity, sand waves still show a net migration (Besio et al., 2003, 2004, 2008; Jiang et al., 2014). This result indicates that the amplitude differences of constituents are not the direct reason for the sand wave bilateral reverse migration in small area.

Comparing the bedload transport summation with time of different profiles under pure tidal conditions and synthesised conditions, it can be found that the summations for profiles $\mathrm{W} 1$ and $\mathrm{C} 2$ are located above the $\mathrm{X}$-axis if considering the residual velocity, but the summation in profile E3 still lies below the X-axis. This result indicates that the northward residual velocity causes the northward sand wave migration, and the impact degree directly depends on the magnitude of the residual velocity. When the residual velocity is $0.0036 \mathrm{~m} / \mathrm{s}$, the southward sand wave migration caused by the tidal nonlinear impact is cancelled, and the sand wave finally migrates northwards; a residual velocity of only $0.0001 \mathrm{~m} / \mathrm{s}$ is insufficient to cancel the southward migration trend caused by the tidal nonlinear impact. A residual velocity must exist between the above two values with which the impact of the residual velocity and tidal nonlinear current can be balanced such that the sand wave hardly moves. This value was obtained as $0.0022 \mathrm{~m} / \mathrm{s}$ after numerical experiments Fig. 9.

This analysis discloses that the sand wave migration process is caused by differences of orders of magnitude of the residual velocity over space, which is significantly affected by the surrounding topography of the sand wave area.

\section{Conclusion}

To investigate the complex phenomenon of one-group small-scale sand wave bilateral reverse migration in a shallow shelf sea in the northern South China Sea, whose mechanism isn't clearly yet, this paper built a three-dimensional wave-current coupling numerical module and sand transport module to successfully simulate this feature and perform relative analysis on the characteristics of the current and bilateral reverse migration formation mechanism. The following conclusions are obtained.

1. The wave-current coupling sand wave migration model introduced in this paper is able to successfully simulate a one-group smallscale sand wave bilateral reverse migration. This model completely and sufficiently considers the ocean environment characteristics of the surrounding sea area. The use of the grid-nesting method to efficiently obtain the small-scale current characteristics difference is the key factor in modelling of sand wave bilateral reverse migration.

2. An analysis framework is proposed to illustrate the bilateral reverse migration happens. It takes bottom friction velocity as the inspecting physical quantity and divides it into tidal, residual and short-term fluctuation components through harmonic analysis; with a method based on bedload transport calculation, the contributions of the above three parts are determined. No obvious difference was

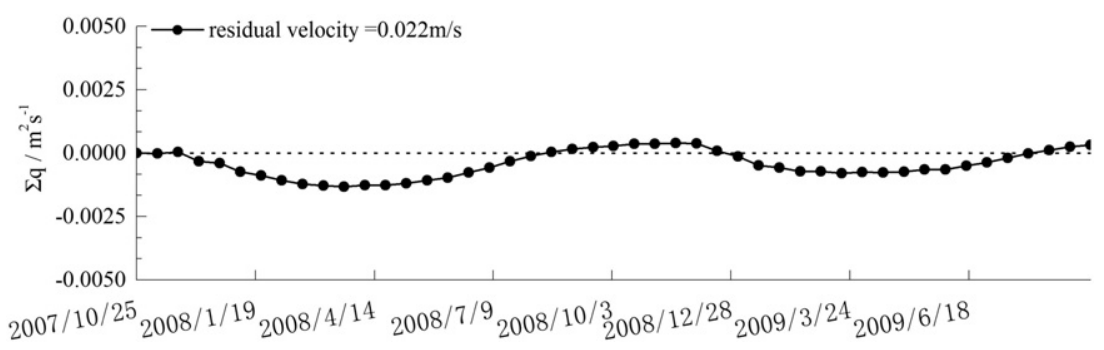

Fig. 9. Time series of bedload transport summation with a residual velocity of $0.022 \mathrm{~m} / \mathrm{s}$ in profile E3. 
observed in the tidal constituent phase angles among three typical profiles, but the amplitudes of the $\mathrm{K} 1, \mathrm{O} 1$, and $\mathrm{M} 2$ constituents displayed certain difference. The residual velocity in profiles $\mathrm{W} 1$ and $\mathrm{C} 2$ to the west and on the back of the sand ridge is larger in magnitude than that in profile E3 to the east of the sand ridge; however, their directions are consistently northward. The differences in the residual velocity at the two sides of the sand ridged are closely related to the surrounding sea floor topography. The comparison shows that short-term meteorological factors and season variation anomalies have little influence on the long-term sand wave migration trend, which is primarily controlled by tidal constituents and residual velocity.

3. The mechanism for bilateral reverse migration of one-group smallscale sand waves in a small shallow shelf sea is disclosed. Via comparison of bedload transport summation over time under the pure tidal and synthesised velocity conditions, it is found that under nonlinear pure tidal impact, the sand waves migrate southwards, and the northward residual velocity will cancel the influences of the tide constituents. There exists a critical value for the residual velocity; when the residual velocity is larger than this value, sand waves begin to migrate northwards. The value was determined as $0.0022 \mathrm{~m} / \mathrm{s}$ through numerical experiments. The residual velocity in profiles $\mathrm{W} 1$ and $\mathrm{C} 2$ is larger than this critical value, and the sand waves migrate northward. The residual velocity in profile E3 is two orders of magnitude smaller than the critical value, and the sand waves migrate southward.

Our research shows that the key factor required for prediction of the sand wave migration trend is the tidal characteristics parameter and the residual bottom friction velocity of the sea area. However, the common velocity analysis only addresses the main tidal constituent or obtains fewer tidal constituent parameters. Further research is needed to determine whether the components of the synthesised velocity can be simplified without impacting the accuracy of the sand wave migration prediction. Another challenge is that if the assumption of unchanged sand wave shape during migration is invalid, then another highly efficient and simple sand wave migration direction prediction method must be developed.

\section{Acknowledgement}

This work is supported by the National Natural Science Foundation of China (Grant no. 41406124 and Grant no. 11032007) and the Key Instrument Developing Project of the Chinese Academy of Sciences (Grant no. ZDYZ2012-1-08-02).

\section{References}

Atlas, R., Hoffman, R.N., Bloom, S.C., Jusem, J.C., Ardizzone, J., 1996. A multiyear global surface wind velocity data set using SSM/I wind observations. Bull. Am. Meteorol. Soc. 77 (5) 869-882. http://dx.doi.org/10.1175/1520-0477(1996)077<0869:AMGSWV>2.0.CO;2.

Besio, G., Blondeaux, P., Brocchini, M., Hulscher, S.J.M.H., Idier, D., Knaapen, M.A.F., Nemeth, A.A., Roos, P.C., Vittori, G., 2008. The morphodynamics of tidal sand waves: a model review. Coast. Eng. 55 (7-8), 657-670. http://dx.doi.org/10.1016/j.coastaleng.2007.11.004.

Besio, G., Blondeaux, P., Brocchini, M., Vittori, G., 2003. Migrating sand waves. Ocean Dyn. 53 (3), 232-238. http://dx.doi.org/10.1007/s10236-003-0043-X.

Besio, G., Blondeaux, P., Brocchini, M., Vittori, G., 2004. On the modeling of sand wave migration. J. Geophys. Res. Oceans 109, C04018. http://dx.doi.org/10.1029/2002JC001622.

Blumberg, A.F., Mellor, G.L., 1978. A coastal ocean numerical model. Mathematical Modelling of Estuarine Physics. Springer-Verlag. http://dx.doi.org/10.1029/LN001p0203.

Blumberg, A.F., Mellor, G.L., 1987. A description of a three-dimensional coastal ocean circulation model. Three-Dimensional Coastal Ocean Models. American Geophysical Union. http://dx.doi.org/10.1029/CO004p0001

Boe, R., Bellec, V.K., Dolan, M.F.J. Buhl-Mortensen, P. Buhl-Mortensen, L., Slagstad, D., Rise, L., 2009. Giant sandwaves in the Hola glacial trough off Vesteralen, North Norway. Mar. Geol. 267 (1-2), 36-54. http://dx.doi.org/10.1016/j.margeo.2009.09.008.

Booij, N., Ris, R.C., Holthuijsen, L.H., 1999. A third-generation wave model for coastal regions: 1. Model description and validation. J. Geophys. Res. Oceans 104 (C4), 7649-7666. http://dx.doi.org/10.1029/98JC02622.

Borsje, B.W., De Vries, M.B., Bouma, T.J., Besio, G., Hulscher, S.J.M.H., Herman, P.M.J., 2009 Modeling bio-geomorphological influences for offshore sandwaves. Cont. Shelf Res. 29 (9), 1289-1301. http://dx.doi.org/10.1016/j.csr.2009.02.008.
Borsje, B.W., Roos, P., Kranenburg, W.M., Hulscher, S., 2013. Modeling tidal sand wave formation in a numerical shallow water model: the role of turbulence formulation. Cont. Shelf Res. 60, 17-27. http://dx.doi.org/10.1016/j.csr.2013.04.023.

Boyer, T., Levitus, S., Garcia, H., Locarnini, R., Stephens, C., Antonov, J., 2005. Objective analyses of annual, seasonal, and monthly temperature and salinity for the world ocean on a $0.25^{\circ}$ grid. Int. J. Climatol. 25, 931-945. http://dx.doi.org/10.1002/joc. 1173.

Chen, S.L., Pei, W.B., Tang, Y., 2009. Research on harmonic analysis of one year flow data file. J. Waterw. Harb. 6, 444-447 (in Chinese).

Davies, A.M., Lawrence, J., 1994. Examining the influence of wind and wind wave turbulence on tidal currents, using a three-dimensional hydrodynamic model including wave-current interaction. J. Phys. Oceanogr. 24, 2441-2460. http://dx.doi.org/10. 1175/1520-0485(1994)024<2441:ETIOWA>2.0.CO;2.

der Westhuysen, Van, Zijlema, A.J.M., Battjes, J.A., 2007. Nonlinear saturation-based whitecapping dissipation in SWAN for deep and shallow water. Coast. Eng. 54, 151-170. http://dx.doi.org/10.1016/j.coastaleng.2006.08.006.

Donelan, M.A., Dobson, F.W., Smith, S.D., Anderson, R.J., 1993. On the dependence of sea surface roughness on wave development. J. Phys. Oceanogr. 23, 2143-2149. http:// dx.doi.org/10.1175/1520-0485(1993)023<2143:OTDOSS >2.0.CO;2.

Egbert, G.D., Erofeeva, S.Y., 2002. Efficient inverse modeling of barotropic ocean tides. J. Atmos. Ocean. Technol. 19, 183-204. http://dx.doi.org/10.1175/15200426(2002)019<0183:ЕIMOBO>2.0.CO;2.

Franzetti, M., Le Roy, P., Delacourt, C., Garlan, T., Cancouet, R., Sulchovich, A., Deschamps, A., 2013. Giant dune morphologies and dynamics in a deep continental shelf environment: example of the banc du four (Western Brittany, France). Mar. Geol. 346 (1), 17-30. http://dx.doi.org/10.1016/j.margeo.2013.07.014

Grant, W.D., Madsen, O.S., 1979. Combined wave and current interaction with a rough bottom. J. Geophys. Res. Oceans 84, 1797-1808. http://dx.doi.org/10. 1029/JC084iC04p01797.

Hasselmann, S., Hasselmann, J.H., Allender, J.H., Barnett, T.P., 1985. Computations and parameterizations of the nonlinear energy transfer in a gravity wave spectrum. Part II: parameterizations of the nonlinear transfer for application in wave models. J. Phys. Oceanogr. 15 (11), 1378-1391. http://dx.doi.org/10.1175/1520-0485(1985)015<1378: CAPOTN $>2.0 . \mathrm{CO} ; 2$

Huffman, G.J., Adler, R.F., Morrissey, M., Bolvin, D.T., Curtis, S., Joyce, R., McGavock, B., Susskind, J., 2001. Global precipitation at one-degree daily resolution from multisatellite observations. J. Hydrometeorol. 2, 36-50. http://dx.doi.org/10.1175/15257541(2001)002<0036:GPAODD>2.0.CO;2.

Jiang, W.B., Lin, M., 2011. Application of grid-nesting technique on sandwaves migration simulation I-ultra-high resolution 3D current simulation. Chin. J. Geophys. 54, 712-724. http://dx.doi.org/10.1002/cjg2.1654.

Jiang, W.B., Lin, M., Li, Y., Fan, F.X., Yan, J., 2014. Application of grid-nesting technique on sandwaves migration simulation II-sandwaves migration in Northern South China Sea. Chin. J. Geophys. 57, 355-368. http://dx.doi.org/10.1002/cjg2.20109.

Jing, L., Ridd, P.V., 1996. Wave-current bottom shear stresses and sediment resuspension in Cleveland Bay, Australia. Coast. Eng. 29, 169-186. http://dx.doi.org/10.1016/ S0378-3839(96)00023-3.

Li, Y., Lin, M., Jiang, W.B., Fan, F.X., 2011. Process control of the sand wave migration in Beibu Gulf of the South China Sea. J. Hydrodyn. Ser. B 23, 439-446. http://dx.doi. org/10.1016/S1001-6058(10)60134-5.

Li, Z.W., Yan, J., Luan, Z.D., Wang, X.H., 2010. Analysis on spatial differences of morphology and mobility of the submarine sand waves in Southwest Hainan Island. Mar. Geol. Dev. 26 (7), 24-32 (in Chinese).

Lin, M., Fan, F.X., Li, Y., Yan, J., Jiang, W.B., Gong, D.J., 2009. Observation and theoretical analysis for the sand-waves migration in the North Gulf of South China Sea. Chin. J. Geophys. 52 (3), 776-784 (in Chinese).

Ma, X.C., Fan, F.X., Yan, J., 2011. In-situ monitoring platform for marine sediment dynamics and its application. Mar. Geol. Quat. Geol. 31 (4), 179-185 (in Chinese)

Mellor, G.L., Yamada, T., 1982. Development of a turbulence closure model for geophysical fluid problems. Rev. Geophys. 20 (4), 851-875. http://dx.doi.org/10. 1029/RG020i004p00851.

Meyer-Peter, E., Müller, R., 1948. Formulas for Bed-load Transport. Int. Assoc. Hydraulic Research. 2nd Mtg., Stockholm, pp. 39-64.

Németh, A.A., Hulscher, S.J.M.H., De Vriend, H.J., 2002. Modelling sand wave migration in shallow shelf seas. Cont. Shelf Res. 22, 2795-2806. http://dx.doi.org/10.1016/S02784343(02)00127-9.

Németh, A.A., Hulscher, S.J.M.H., Damme Van, R.M.J., 2004. Modelling sand wave migration and height, comparing model results with data. Marine Sandwave and River Dune Dynamics II. University of Twente, Enschede, The Netherlands, pp. 232-239.

Németh, A.A., Hulscher, S.J.M.H., Van Damme, R.M.J., 2007. Modelling offshore sand wave evolution. Cont. Shelf Res. 27, 713-728. http://dx.doi.org/10.1016/j.csr.2006.11.010.

Orlanski, I., 1976. A simple boundary condition for unbounded hyperbolic flows. J. Comput. Phys. 21 (3), 251-269. http://dx.doi.org/10.1016/0021-9991(76)90023-1.

Pawlowicz, R., Beardsley, B., Lentz, S., 2002. Classical tidal harmonic analysis including error estimates in MATLAB using T-TIDE. Comput. Geosci. 28, 929-937. http://dx. doi.org/10.1016/S0098-3004(02)00013-4.

Phillips, N.A., 1957. A coordinate system having some special advantages for numerical forecasting. J. Meteorol. 14 (2), 184-185. http://dx.doi.org/10.1175/15200469(1957)014<0184:ACSHSS $>2.0$.CO;2.

Signell, R., Beardsley, R., Graber, H., Capotondi, A., 1990. Effect of wave-current interaction on wind-driven circulation in narrow, shallow embayments. J. Geophys. Res. Oceans 95, 9671-9678. http://dx.doi.org/10.1029/JC095iC06p09671.

Smith, W.H.F., Sandwell, D.T., 1997. Global seafloor topography from satellite altimetry and ship depth soundings. Science 277, 1957-1962. http://dx.doi.org/10.1126/ science.277.5334.1956. 
Van Dijk, TaGP, Kleinhans, M.G., 2005. Processes controlling the dynamics of compound sand waves in the North Sea, Netherlands. J. Geophys. Res. Earth Surf. 110. http:// dx.doi.org/10.1029/2004JF000173.

Wang, W.W., Fan, F.X., Li, C.G., Yan, J., 2007. Activity of submarine sand waves and seafloor erosion and deposition in the sea area to the southwest of Hainan Island. Mar. Geol. Quat. Geol. 27 (4), 23-28 (in Chinese).

Yu, L., Jin, X., Weller, R.A., 2008. Multidecade global flux datasets from the objectively analyzed air-sea fluxes (OAFlux) project: latent and sensible heat fluxes, ocean evaporation, and related surface meteorological variables. Woods Hole Oceanographic Institution OAFlux Project Technical Report (OA-2008-01).

Zhang, Y.C., Rossow, W.B., Lacis, A.A., Oinas, V., Mishchenko, M.I., 2004. Calculation of radiative fluxes from the surface to top of atmosphere based on ISCCP and other global data sets: refinements of the radiative transfer model and the input data. J. Geophys. Res. 109, 27. http://dx.doi.org/10.1029/2003JD004457. 